\title{
Biogeographic bases for a shift in crop C: N : P stoichiometries during domestication
}

\author{
Manuel Delgado-Baquerizo, ${ }^{1 *}$ \\ Peter B. Reich, ${ }^{1,2}$ \\ Pablo García-Palacios ${ }^{3}$ and \\ Rubén Milla ${ }^{3}$
}

\begin{abstract}
We lack both a theoretical framework and solid empirical data to understand domestication impacts on plant chemistry. We hypothesised that domestication increased leaf $\mathrm{N}$ and $\mathrm{P}$ to support high plant production rates, but biogeographic and climate patterns further influenced the magnitude and direction of changes in specific aspects of chemistry and stoichiometry. To test these hypotheses, we used a data set of leaf $\mathrm{C}, \mathrm{N}$ and $\mathrm{P}$ from 21 herbaceous crops and their wild progenitors. Domestication increased leaf $\mathrm{N}$ and/or $\mathrm{P}$ for $57 \%$ of the crops. Moreover, the latitude of the domestication sites (negatively related to temperature) modulated the domestication effects on $\mathrm{P}(+), \mathrm{C}(-), \mathrm{N}: \mathrm{P}(-)$ and $\mathrm{C}: \mathrm{P}(-)$ ratios. Further results from a litter decomposition assay showed that domestication effects on litter chemistry affected the availability of soil $\mathrm{N}$ and P. Our findings draw attention to evolutionary effects of domestication legacies on plant and soil stoichiometry and related ecosystem services (e.g. plant yield and soil fertility).
\end{abstract}

\section{Keywords}

Crops, decomposition, growth rate hypothesis, nutrient cycling, soil age hypothesis, T-physiology hypothesis.

Ecology Letters (2016) 19: 564-575

\section{INTRODUCTION}

The domestications of certain wild plants were pivotal cultural and evolutionary events for humankind (Larson et al. 2014). During the process of domestication, humans selected plant phenotypes to promote yield and traits that were beneficial to their own interests (Evans 1993; Hancock 2004; Doebley et al. 2006). These traits included, but were not limited to, size of harvestable organisms, plant growth rates, loss of seed dispersal and plant defence mechanisms and loss of photoperiod sensitivity (Harlan et al. 1973; Meyer \& Purugganan 2013; Milla et al. 2014; Turcotte et al. 2014). For example, domesticated plants have been recently reported to have higher final aboveground biomass than their wild progenitors when both of them are grown under common garden regimes for equal time spans (Milla et al. 2014; Turcotte et al. 2014). Because of selection for agronomic traits and breeding in resource-rich and predictable systems, such as agricultural fields, domestication also promoted multiple indirect and unintentional effects on plant phenotypes (Milla et al. 2015). For instance, human selection for increased crop productivity reduced plant defences against generalist herbivores (Turcotte et al. 2014) and increased plant nutrient uptake (Denison 2012; Bogaard et al. 2013; Araus et al. 2014; but see Milla et al. 2014), potentially altering plant $\mathrm{C}: \mathrm{N}$ : $\mathrm{P}$ ratios. Plant stoichiometry plays a critical role in controlling ecosystem functions and services, such as soil fertility and plant yield (Elser et al. 2000; Sardans et al. 2012; Zechmeister-Boltenstern et al. 2015). Thus, understanding the side effects of domestication on plant

${ }^{1}$ Hawkesbury Institute for the Environment, Western Sydney University, Penrith, 2751 New South Wales, Australia

${ }^{2}$ Department of Forest Resources, University of Minnesota, St. Paul, MN 55108, USA elemental stoichiometry, and whether environmental factors modulate such effects, is of paramount importance to assess agricultural impacts on ecosystem functioning. Although a novel theoretical framework based on ecological principles is emerging to explain unintentional effects of domestication on plant phenotypes (e.g. Milla et al. 2015), we still lack solid empirical data to put it to work.

During the early stages of agriculture, humans selected fastgrowing and productive wild plant species (Tribouillois et al. 2015) that, after evolving under cultivation, generally became larger plants than their progenitors (Milla et al. 2014) which invested less in resistance against pests, diseases and herbivory (Meyer et al. 2012). Fast-growing organisms require high levels of nitrogen $(\mathrm{N})$ and phosphorus $(\mathrm{P})$ to maintain high production rates of $\mathrm{P}$ - and $\mathrm{N}$-rich organelles and molecules such as ribosomes, ATP, DNA, RNA and rubisco. Hence, N and $\mathrm{P}$ are common co-limiters of plant growth (Growth rate hypothesis; Reich et al. 1991; Elser et al. 2000; Peñuelas \& Sardans 2009; Ågren 2008). As a consequence of selection for fast growth rates, domesticated plants may have evolved to increase overall nutrient uptake (e.g. $\mathrm{N}$ and $\mathrm{P}$ ). Moreover, domesticated plants may also invest relatively less $\mathrm{C}$ and $\mathrm{N}$ in structures such as cell walls and structural proteins (e.g. structural defences against pests) and require more $\mathrm{P}$ (thus lower $\mathrm{C}: \mathrm{P}$ and $\mathrm{N}: \mathrm{P}$ ), to support higher energy demands of photosynthesis, respiration, storage, solute transfer and cell division, than their wild progenitors. Intriguingly, a previous study comparing 24 crops with their wild progenitors did not find any consistent effects of domestication across taxa on
${ }^{3}$ Área de Biodiversidad y Conservación, Departamento de Biología, Geología, Física y Química Inorgánica, Escuela Superior de Ciencias Experimentales y Tecnología, Universidad Rey Juan Carlos, c/Tulipán s/n, 28933 Móstoles, Spain *Correspondence: E-mail: M.DelgadoBaquerizo@westernsydney.edu.au 
total $\mathrm{N}$ and $\mathrm{P}$ concentrations in leaf litter (García-Palacios et al. 2013), although an overall decrease in $C$ in plant litter was observed with domestication. Instead, García-Palacios et al. (2013) found that domestication effects on leaf litter $\mathrm{N}$ and $\mathrm{P}$ were highly taxon dependent, ranging from crops where $\mathrm{N}$, but not $\mathrm{P}$, was higher in domesticated lines than in their wild progenitors (e.g. chilli pepper) to crops where $\mathrm{P}$, but not $\mathrm{N}$, increased during evolution under cultivation (e.g. wheat). Exploring the ability of environmental factors to explain how the effects of domestication on plant $\mathrm{N}$ and $\mathrm{P}$ are taxon dependent may shed some light on the apparent inconsistency of the Growth rate hypothesis when accounting for elemental stoichiometry in crop species.

To account for the inconsistent response of plant chemistry to domestication events across crop species, we make use of the large body of ecological theory and empirical evidence illustrating biogeographic and climatic constraints on global nutrient stoichiometry (Reich \& Oleksyn 2004; Peñuelas \& Sardans 2009). On average, tropical soils are older and have less $\mathrm{P}$ compared to soils from mid-latitudinal regions, where $\mathrm{N}$ is the major growth-limiting nutrient (Reich \& Oleksyn 2004). Consequently, soils and plants from tropical latitudes have lower $\mathrm{P}$ and $\mathrm{N}$ availability, and higher $\mathrm{C}: \mathrm{P}$ and $\mathrm{N}: \mathrm{P}$ ratios, than those from middle and high latitudes (Soil age hypotheses; Reich \& Oleksyn 2004). Besides latitudinal gradients in soil substrate age, temperature-related plant physiological constraints can also drive $\mathrm{C}: \mathrm{N}: \mathrm{P}$ plant and soil stoichiometries at a global scale (T-plant physiology hypothesis; Crews et al. 1995; Reich \& Oleksyn 2004). Thus, biogeographic and climatic constraints related with the geographic location (i.e. distance from the equator) of the domestication events may help to explain why the effects of domestication on plant $\mathrm{N}$ and $\mathrm{P}$ are taxon dependent.

Herein we hypothesise that domestication promoted an increase in $\mathrm{N}$ and $\mathrm{P}$ in plant tissues, but a decrease in $\mathrm{C}$ : $\mathrm{P}$ and $\mathrm{N}$ : $\mathrm{P}$, to support fast production rates (i.e. lower investment in structure vs. high energy demands; Growth rate hypothesis; Elser et al. 2000; Peñuelas \& Sardans 2009; Fig. 1). However, considering the importance of biogeography and climate in controlling soil and plant $\mathrm{C}, \mathrm{N}$ and $\mathrm{P}$ stoichiometry (Reich \& Oleksyn 2004; Fig. 1), we further hypothesise that distance from the equator and temperature at domestication areas modulated the domestication effect on soil and plant chemistry, ultimately driving shifts in $\mathrm{C}, \mathrm{N}$ and $\mathrm{P}$ stoichiometry during crop evolution (Substrate age and TPlant physiology hypotheses; Reich \& Oleksyn 2004; Fig. 1). As a result, we posit that even though domesticated plants are expected to generally have a higher leaf $\mathrm{N}$ and $\mathrm{P}$ contents than their wild progenitors, increases in leaf $\mathrm{P}$ during domestication are more likely to happen in the middle latitudes where soil $\mathrm{P}$ is more abundant, but soil $\mathrm{N}$ is a major limiting nutrient (e.g. wheat in Fig. 1). Similarly, increases in leaf $\mathrm{N}$ during domestication may have been more common for crops in the tropical regions, where soil $\mathrm{N}$ is more abundant, but $\mathrm{P}$ is often depleted (e.g. chilli pepper in Fig. 1). As plant stoichiometry largely drives relevant ecosystem services and functions like nutrient cycling, litter decomposition and plant productivity (Zechmeister-Boltenstern et al. 2015 for review), we also expect the previously described plant chemical shifts

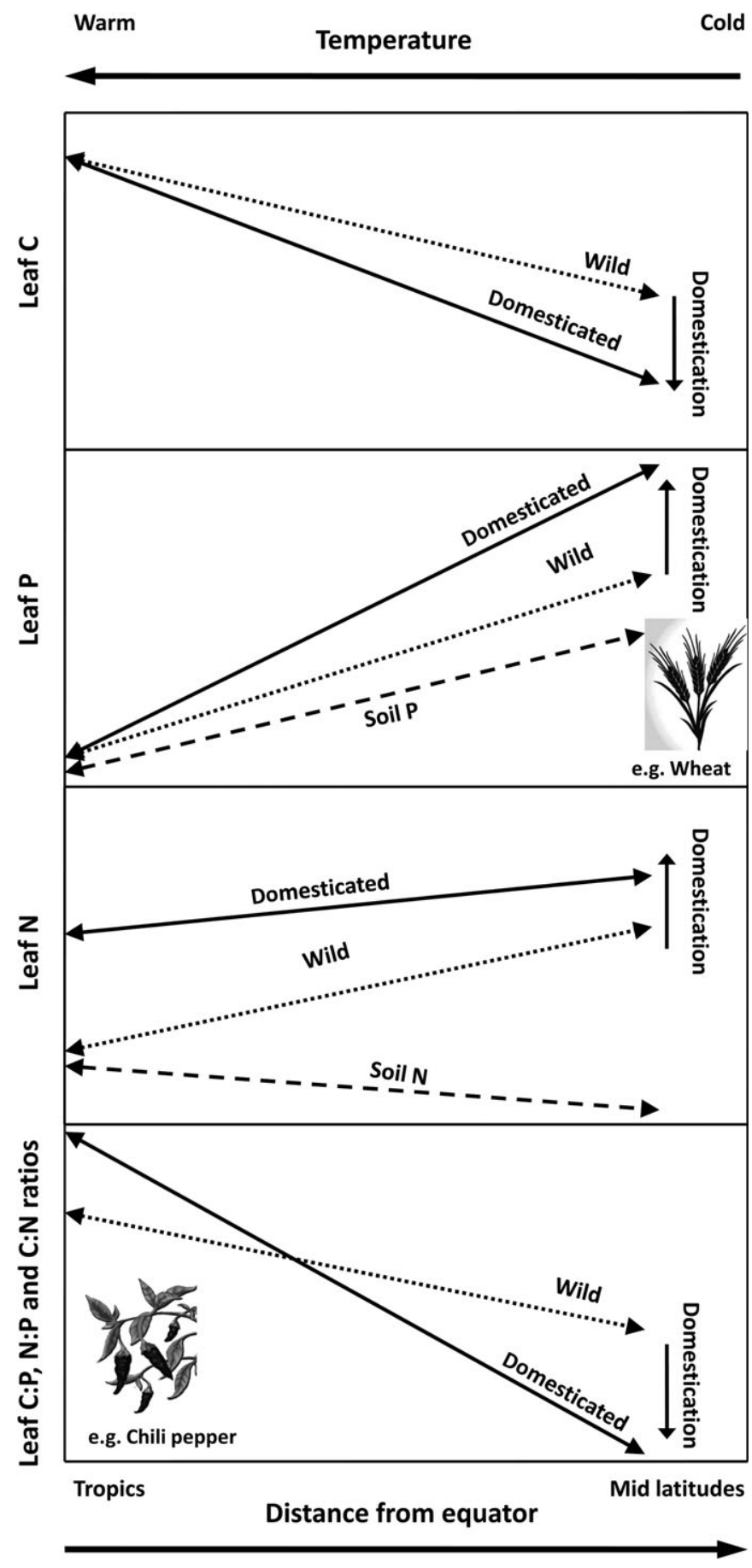

Figure 1 Conceptual framework exploring the effects of domestication on leaf $\mathrm{C}, \mathrm{N}, \mathrm{P}$ concentrations and ratios. Distance from the equator modulates the availability of leaf C, N and P (Reich \& Oleksyn 2004). The further from the equator the lower the leaf $\mathrm{C}$ and $\mathrm{C}: \mathrm{P}$ and $\mathrm{N}$ : $\mathrm{P}$ ratios (blue and black lines), but the higher the availability of leaf $\mathrm{N}$ and $\mathrm{P}$ (red and green lines). Hypothesis: Domestication may push an increase in $\mathrm{N}$ and $\mathrm{P}$ in plant tissues, but a decrease in $\mathrm{C}$, to support high plant production rates (energy vs. structure; Growth rate hypothesis); however, distance from the equator of the domestication site and temperaturerelated plant physiological constrains (i.e. the colder, the lower the $\mathrm{C}$ fixation via photosynthesis per unitary $\mathrm{N}$ and $\mathrm{P}$ investment in productive tissue) modulates the domestication effect on soil and plant chemistry, ultimately driving shifts in $\mathrm{C}, \mathrm{N}$ and $\mathrm{P}$ stoichiometry during plant domestication (T-Plant physiology and Substrate age hypotheses). 
to impact ecosystem processes. Thus, we further explore whether shifts in plant chemistry during domestication might have a legacy impact on ecosystem processes such as nutrient cycling (i.e. via litter decomposition) on the lands where these crops are currently growing.

\section{METHODS}

\section{Study design}

We selected 21 taxonomically diverse herbaceous crops (Table S1). For each crop we obtained seed lots of two accessions: one representative of a modern, domesticated stage of the species, and another of its most probable wild progenitor (Table S1). The focal domesticated and wild progenitors were grown under the same soil conditions during the spring of 2011 in a common garden at the plant growth facilities of Rey Juan Carlos University, located in Móstoles, central Spain $\left(40^{\circ} 18^{\prime} 48^{\prime \prime} \mathrm{N}, 38^{\circ} 52^{\prime} 57^{\prime \prime} \mathrm{W}, 632 \mathrm{~m}\right.$ a.s.l.; see GarcíaPalacios et al. 2013 for details on this set up). Our species belong to families Poaceae (30\%), Solanaceae (20\%), Asteraceae (20\%), Fabaceae (15\%), Amaranthaceae (5\%), Malvaceae $(5 \%)$ and Brassicaceae $(5 \%)$. About $72 \%$ of these species are forbs (i.e. herbaceous flowering plants that are neither graminoids nor legumes) and $28 \%$ grasses. These species have C3 photosynthesis, except Amaranthus, Pennisetum and $\mathrm{Zea}$ that have $\mathrm{C} 4$ photosynthesis. Moreover, all annual or biennial plants and most of the species $(\sim 72 \%)$ are cultivated for their fruits or seeds.

\section{Total $\mathbf{N}$ and $\mathbf{P}$ in green leaves and in litter}

Green leaves at vegetative maturity were collected from three individuals per accession; later at the end of the growing season, naturally senescent leaf litter was also collected from these accessions. Green leaves were oven dried at $70{ }^{\circ} \mathrm{C}$ for $48 \mathrm{~h}$ before chemistry analyses. Litter was air dried for 1 month. Total $\mathrm{C}$ and $\mathrm{N}$ were analysed in an Elementar varioMAX N/CN (Hanau, Germany), and $\mathrm{P}$ using vanadomolybdic colorimetry (García-Palacios et al. 2013). The $\mathrm{C}: \mathrm{N}: \mathrm{P}$ ratios were calculated from these variables at the sample level.

\section{Impact of litter chemistry on soil properties}

A total of 30 soil cores $(0-10 \mathrm{~cm}$ deep) from two soil types were randomly sampled from two roadside grasslands from central Spain. The first site was a 2-year-old roadside grassland, and represents an early successional stage (soil A; $39^{\circ} 47^{\prime} \mathrm{N}, 3^{\circ} 12^{\prime} \mathrm{W}, 731 \mathrm{~m}$ a.s.1.); the other was a $>20$-yearold roadside grassland representing a late successional stage (soil B; $40^{\circ} 22^{\prime} \mathrm{N}, 03^{\circ} 53^{\prime} \mathrm{W} ; 615 \mathrm{~m}$ a.s.l.). These two soils were selected because of their contrasting characteristics (García-Palacios et al. 2013). For the top $10 \mathrm{~cm}$, soil pH ranged between 8.3 and 7.2 and organic $\mathrm{C}$ between 0.8 and 2.3\% for soils A and B, respectively. Soil samples were bulked by site to get a representative microbial community, homogenised, sieved (2-mm mesh) and kept cold in the fridge until laboratory preparation. We used leaf litter from a subset of 7 of the 21 crops (i.e. a total of 14 litter types belonging to domesticated and wild progenitor accessions of Beta, Helianthus, Lactuca, Pennisetum, Zea, Amaranthus and Lycopersicon). The litter decomposability assay is fully explained in García-Palacios et al. (2013) and Delgado-Baquerizo et al. (2015). Here, we used the experimental setup of those studies, supplemented with de novo analyses of available $\mathrm{C}, \mathrm{N}$ and $\mathrm{P}$ in the soils, to explore whether a shift in litter chemistry derived from domestication impacts upon the availability and stoichometry of $\mathrm{C}, \mathrm{N}$ and $\mathrm{P}$ in soils. In brief, sixty grams of two soil types (A and B) were introduced into $250-\mathrm{mL}$ airtight mason jars and moisture adjusted to $50 \%$ water holding capacity. A total quantity of $0.75 \mathrm{~g}$ of air-dried litter was then placed on top of the soil surface. We established five microcosms for each crop (7) $\times$ accession (2) $\times$ soil type (2) combination, rendering a total of 140 microcosms. The microcosms were placed in a plant growth chamber at $20{ }^{\circ} \mathrm{C}, 95 \%$ air humidity and dark conditions for 9 weeks (García-Palacios et al. 2013). The use of leaf litter instead of green leaves is more pertinent to investigate afterlife plant effects on ecosystem processes (Cornelissen et al. 2004), especially in agroecosystems where crop residues are key sources of organic matter inputs. Importantly, total $\mathrm{C}, \mathrm{N}$ and $\mathrm{P}$ in green leaves were highly correlated to those in leaf litter $(P<0.05$ in all cases; Table S2).

After incubation, the concentration of dissolved organic $\mathrm{C}$ was measured from $\mathrm{K}_{2} \mathrm{SO}_{4}$ 0.5-M extracts by using a TOC analyser (TOC-Vsch, Shimadzu, Kyoto, Japan). Total available $\mathrm{N}$ (i.e. sum of dissolved organic and inorganic $\mathrm{N}$ ) was determined from these $\mathrm{K}_{2} \mathrm{SO}_{4}$ 0.5-M extracts by using the indophenol blue method (read absorbance at $655 \mathrm{~nm}$ ). Then, the potassium persulphate digestion was placed in an autoclave at $121{ }^{\circ} \mathrm{C}$ over $55 \mathrm{~min}$ and, finally, the digested extract subsamples were incubated with Devarda alloy overnight (Delgado-Baquerizo \& Gallardo 2011). Total available P (i.e. sum of organic and inorganic Olsen P) was determined as described in Tiessen \& Moir (1993), based on its reaction with ammonium molybdate. The ratios of available $\mathrm{C}: \mathrm{N}$ : $\mathrm{P}$ were calculated from these variables at a sample level.

\section{Latitudinal patterns in plant domestication}

One of the main goals of this study is to explore the role of absolute latitude (i.e. distance from the equator) of domestication sites in controlling the effects of domestication on plant stoichiometry. To obtain information on the most probable location for the domestication events of each crop, we used the online Global Biodiversity Information Facility (http:// www.gbif.org/). Within that database, we searched for the location of each wild progenitor species using only georeferenced data and with no issues on coordinates. We filtered the output of those searches keeping only coordinates within the native range of each of the species. We then calculated absolute latitude of the domestication site from those data, and averaged it by species. Our proxy for the location of the domestication events was highly congruent (Pearson's $r=0.953 ; P<0.001$; Fig. S1) with data from Meyer et al. (2012), supporting the reliability of our approach. We further grouped the different crop species into two categories based 
on the geographical location of their domestication sites: tropics (absolute latitude $0-23^{\circ}$ ) and middle latitudes (absolute latitude $>23^{\circ}$ ).

\section{Climate at plant domestication sites}

To evaluate the role of ancient temperature records in controlling changes in plant chemistry during domestication, we obtained information on the average temperature in the midHolocene (about 6000 years ago) for each location, using global climate models. We selected this date as many plant domestication processes were taking place during that period (Larson et al. 2014). In particular, we used the Beijing Climate Center Climate System Model (BCC_CSM1.1) available from http://www.worldclim.org (Hijmans et al. 2005; Wu et al. 2013) at a $\sim 1 \mathrm{~km}$ resolution, which provides climatic information from the mid-Holocene. We used coordinates obtained from the online Global Biodiversity Information Facility (http://www.gbif.org/) for each domestication site to generate average temperature data. The selection of the average temperature in the mid-Holocene as our climatic proxy was supported by further analysis (Appendix S1).

\section{Testing differences in plant chemistry between crop and wild progenitors}

We first tested for differences in green leaf chemistry and stoichiometry among crops (i.e. taxa) and domestication statuses (i.e. domesticated vs. wild progenitor) by using a two-way ANOVA with accession as a fixed factor and crop identity as a random factor. We then explored differences in green leaf chemistry and stoichiometry (leaf $\mathrm{C}, \mathrm{N}$ and $\mathrm{P}$ concentration and ratios) within each pair of crop/wild progenitors using a one-way ANOVA with crop identity as a random factor. Please note that our data followed assumptions of normality and homoscedasticity required for these analyses (Table S3). Residuals from one-way ANOVA analyses were also normally distributed (Table S4). Moreover, we repeated statistical analyses using two alternative approaches: Generalised Linear Model using gamma distribution and one-way PERMANOvAS (Anderson 2001) using the Euclidean distance.

\section{Domestication effect on plant chemistry and stoichiometry}

To evaluate the relative importance of domestication on leaf nutrient concentrations and ratios across latitudinal and temperature gradients, we calculated the effect size of $\mathrm{C}, \mathrm{N}, \mathrm{P}$ and $\mathrm{C}: \mathrm{P}, \mathrm{N}: \mathrm{P}$ and $\mathrm{C}: \mathrm{N}$ ratios as $\operatorname{LnRR}(\mathrm{X})=\ln$ $\left(X_{\text {dom }}+1\right)-\ln \left(X_{\text {wild }}+1\right)$, where $X_{\text {dom }}$ and $X_{\text {wild }}$ are mean values for either $\mathrm{C}, \mathrm{N}$ and $\mathrm{P}$ or $\mathrm{C}: \mathrm{P}, \mathrm{N}: \mathrm{P}$ and $\mathrm{C}: \mathrm{N}$ ratios in green leaves for domesticated and wild progenitor accessions for each crop, respectively. LnRR is a unitless index, which ranges from $\infty$ to $+\infty$ and estimates the size of the impact and its direction (Hedges et al. 1999). A zero $\ln R \mathrm{R}$ value means no domestication effect on plant stoichiometries compared to the wild progenitor. Positive/negative values indicate an increase/decrease in plant $\mathrm{C}, \mathrm{N}, \mathrm{P}$ and $\mathrm{C}: \mathrm{P}, \mathrm{N}: \mathrm{P}, \mathrm{C}: \mathrm{N}$, compared to the wild progenitor. Original LnRR data were normally distributed (Tables S5). Moreover, three other effect-size metrics were computed for testing consistency of our selected size effect (LnRR): Percentage Change ((XdomXwild $) /$ Xwild $\times 100), \quad$ RII $\quad((X d o m-X$ wild $) /(X d o m+X$ wild $))$ and Cohen's D ((Xdom-Xwild)/SDpooled).

\section{Testing relationships between latitude and climate with domestication effects on plant chemistry}

We analysed the linear relationship between absolute latitude and average temperature (i.e. in the mid-Holocene) of each domestication site with the effect size of domestication on total $\mathrm{N}, \mathrm{P}$ and $\mathrm{N}$ : $\mathrm{P}$ ratio in green leaves (i.e. relative difference between crop and wild progenitors, as calculated using the size effect of domestication, LnRR). Residuals from the explored regressions between distance from the equator and averaged temperature in mid-Holocene with LnRR data were normally distributed (Tables S6). Moreover, we explored the correlation (Pearson's r) between absolute latitude and average temperature (i.e. in the mid-Holocene) with Percentage Change, RII and Cohen's D indexes.

\section{RESULTS}

We found a strongly significant interaction between the two main factors (crop identity $\times$ domestication statuses) in all cases: $\mathrm{C}(\mathrm{F}=12.90, P<0.001), \mathrm{N}(\mathrm{F}=7.34, P<0.001), \mathrm{P}$ $(\mathrm{F}=17.49, P<0.001), \mathrm{N}: \mathrm{P}(\mathrm{F}=10.78, P<0.001), \mathrm{C}: \mathrm{N}$ $(\mathrm{F}=16.95, P<0.001)$ and $\mathrm{C}: \mathrm{P}(\mathrm{F}=10.33, P<0.001)$, suggesting that the effects of accession on plant chemistry and stoichiometry are indeed highly taxon dependent, supporting the results of García-Palacios et al. (2013) for leaf litter.

Domestication tended to promote an increase in green leaf P (48\% of cases), but a decrease in leaf $\mathrm{C}$ and $\mathrm{C}: \mathrm{P}$ and $\mathrm{N}$ : $\mathrm{P}$ ratios $(48 \%$ of species pairs; Figs 2 and S2; Tables 1 and S7). However, 9, 14, 14 and $9 \%$ of the cases showed stoichiometric patterns opposed to expectations, for leaf $\mathrm{C}, \mathrm{P}$, $\mathrm{C}: \mathrm{P}$ and $\mathrm{N}: \mathrm{P}$, respectively (Figs 2 and S2). We did not find generalised patterns for domestication-driven shifts in leaf $\mathrm{N}$ or $\mathrm{C}: \mathrm{N}$ ratios (Figs 2 and S2; Tables 1 and S7). Leaf $\mathrm{N}$ either increased $(33 \%)$, decreased $(19 \%)$ or remained statistically constant $(38 \%)$ during the 21 domestication processes examined. Similarly, C : N ratios showed diverse reactions to domestication (24\% increase, $24 \%$ decrease and $52 \%$ stationary) (Tables 1 and S7; Fig. S2). Moreover, $P$-values from one-way ANOvA analyses were highly correlated to those with Generalised Linear Model (Pearson's $r>0.97 ; \quad P<0.001$; Table S8) and one-way PERMAnovas (Pearson's $r>0.92$; $P<0.001$; Table S8) providing further scientific rigour to our results.

Location of the domestication events played a key role modulating the effect of domestication on plant chemistry and stoichiometry. Shifts in plant chemistry and stoichiometry differed between crops raised at middle latitudinal (absolute latitude $\geq 23^{\circ}$ ) and tropical regions (absolute latitude $\leq 23^{\circ}$; Marsh \& Kaufman 2013). Crops domesticated in the middle latitudes showed higher green leaf $\mathrm{P}$, but lower leaf $\mathrm{C}, \mathrm{N}$ and $\mathrm{C}: \mathrm{P}$ and $\mathrm{N}: \mathrm{P}$ ratios, compared to their wild progenitors (Fig. 2; Table 1; Fig. S2). From the 12 middle latitude species pairs evaluated, $50 \%$ of the crops showed significantly higher 

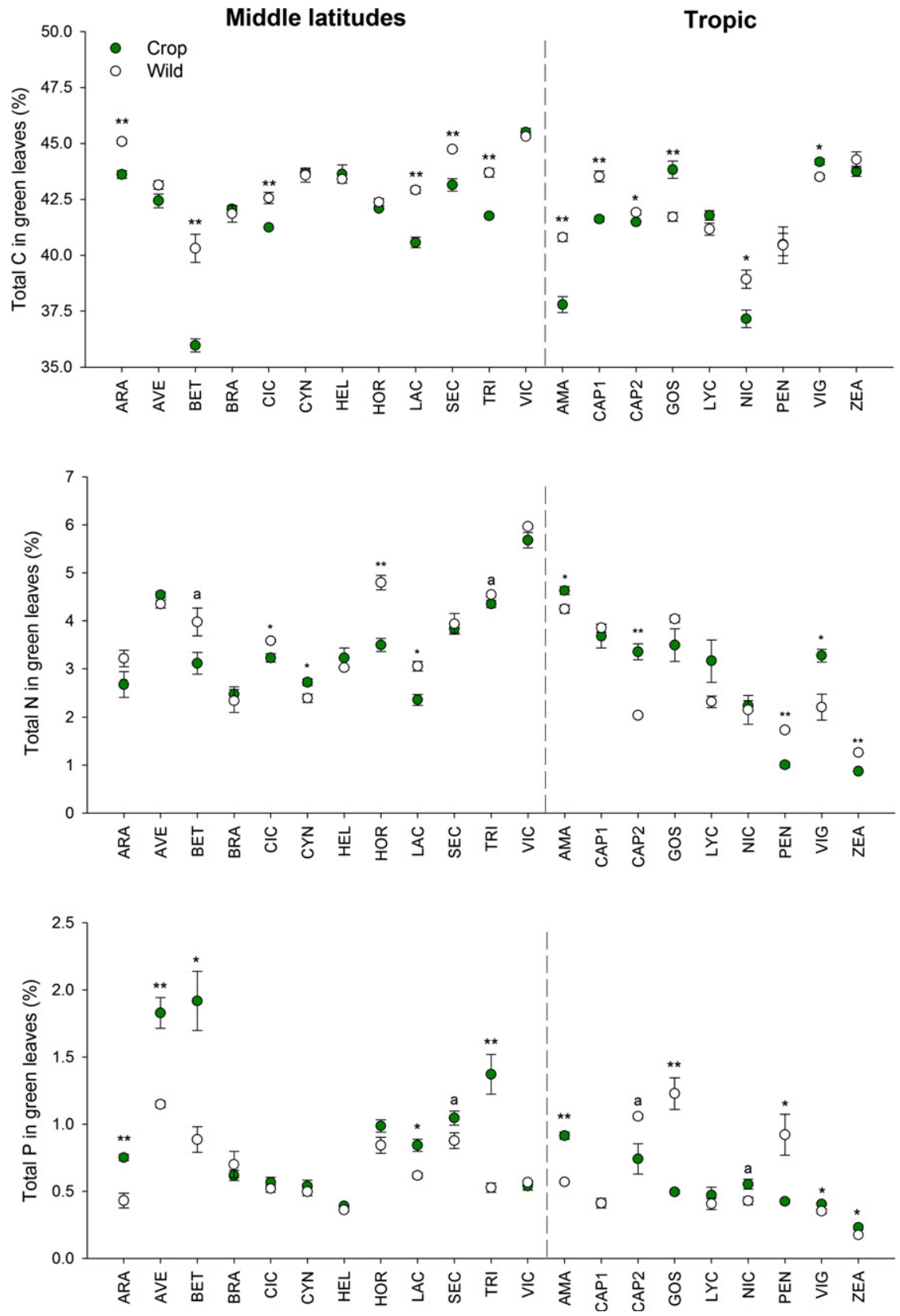

Figure 2 Mean values $( \pm \mathrm{SE})$ for $\mathrm{C}, \mathrm{N}$ and $\mathrm{P}$ concentrations in green leaves for 21 taxonomically diverse herbaceous crops and their wild ancestors $(n=3)$. Differences between domesticated and wild progenitor accessions are as follows: ${ }^{\text {a }} P \leq 0.10, * P<0.05$ and $* * P<0.01$.

$\mathrm{P}$ concentrations, and 50,42, 50 and $67 \%$ of them showed lower $\mathrm{C}, \mathrm{N}$ and $\mathrm{C}: \mathrm{P}$ and $\mathrm{N}: \mathrm{P}$ ratios, respectively, compared to their wild progenitors (Figs 2 and S2; Table 1). Results for the nine tropical crops evaluated (absolute latitude $\leq 23^{\circ}$ ) were less consistent. We found both significant increases and decreases in green leaf C (22 vs. 44\%), N (33 vs. $22 \%), \mathrm{P}(44$ vs. $33 \%)$ and $\mathrm{C}: \mathrm{P}(33$ vs. $55 \%), \mathrm{N}: \mathrm{P}(22$ vs. $22 \%)$ and $\mathrm{C}: \mathrm{N}(22$ vs. $33 \%)$ ratios.

Supporting our conceptual framework (Fig. 1), and in line with Reich \& Oleksyn (2004), we found positive relationships between absolute latitude and leaf $\mathrm{N}$ (Pearson's $r=0.314$; $P=0.043$ ) and $\mathrm{P}$ (Pearson's $r=0.397 ; P=0.009$ ), and negative relationships between absolute latitude and C : P (Pear- son's $r=-0.388 ; \quad P=0.011$ ) and $\mathrm{C}: \mathrm{N}$ ratios (Pearson's $r=-0.328 ; P=0.034, n=42$ in all cases). Similarly, higher temperatures in the mid-Holocene decreased leaf N (Pearson's $r=-0.336 ; \quad P=0.029$ ), but increased $\mathrm{C}: \mathrm{P} \quad$ (Pearson's $r=-0.384 ; \quad P=0.012$ ) and $\mathrm{C}: \mathrm{N}$ (Pearson's $r=-0.420$; $P=0.006)$.

Notably, the way plant chemistry and stoichiometries of each crop species reacted to domestication was significantly related to the latitude of domestication sites and to the old climate in those regions (Figs 3 and 4). Absolute latitude was positively related to LnRR-P and negatively related to LnRR$\mathrm{C}$ and LNRR-N : $\mathrm{P}$ and $-\mathrm{C}: \mathrm{P}$ ratios (Figs 3 and 4; $P<0.05)$. Moreover, the mid-Holocene temperature at 


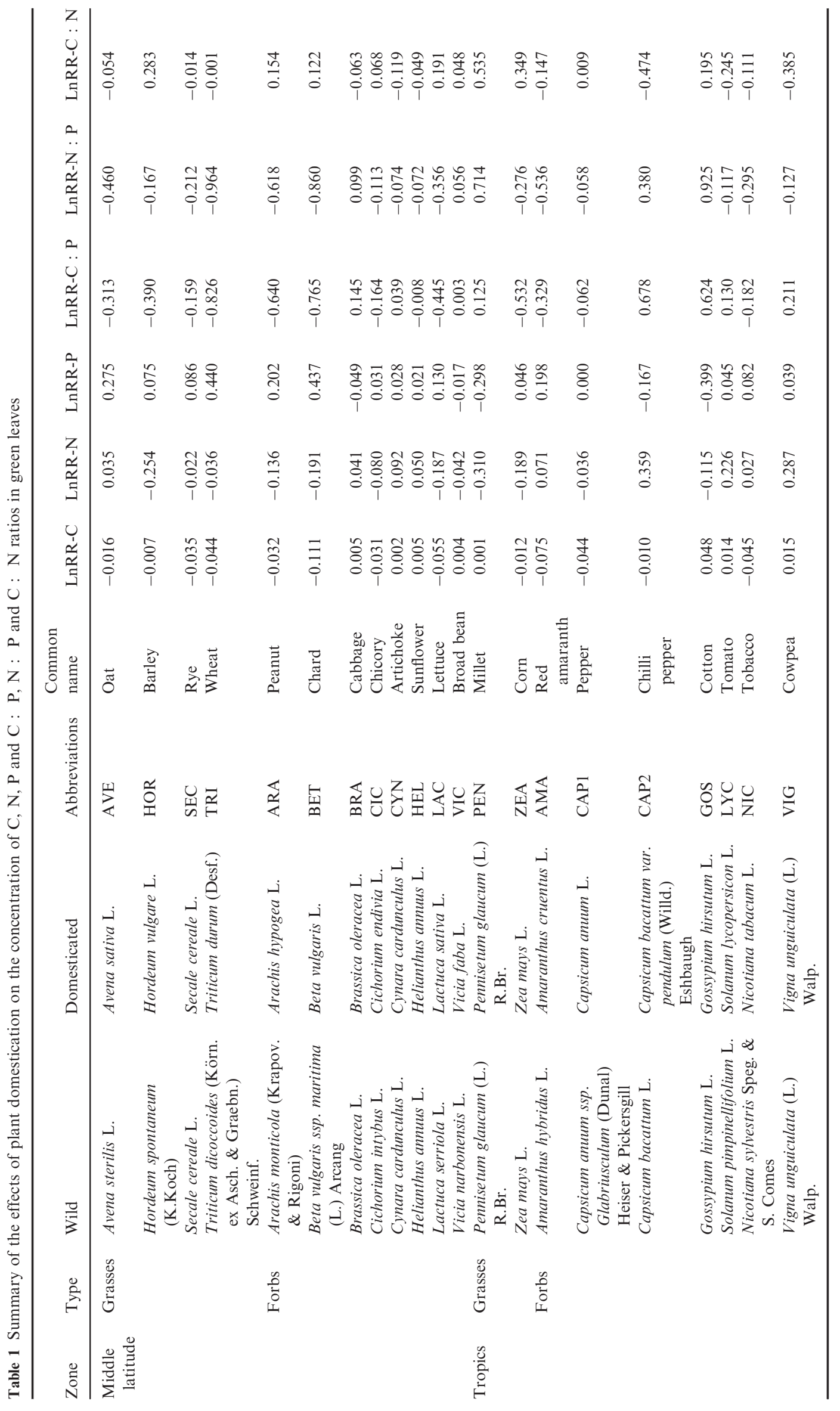



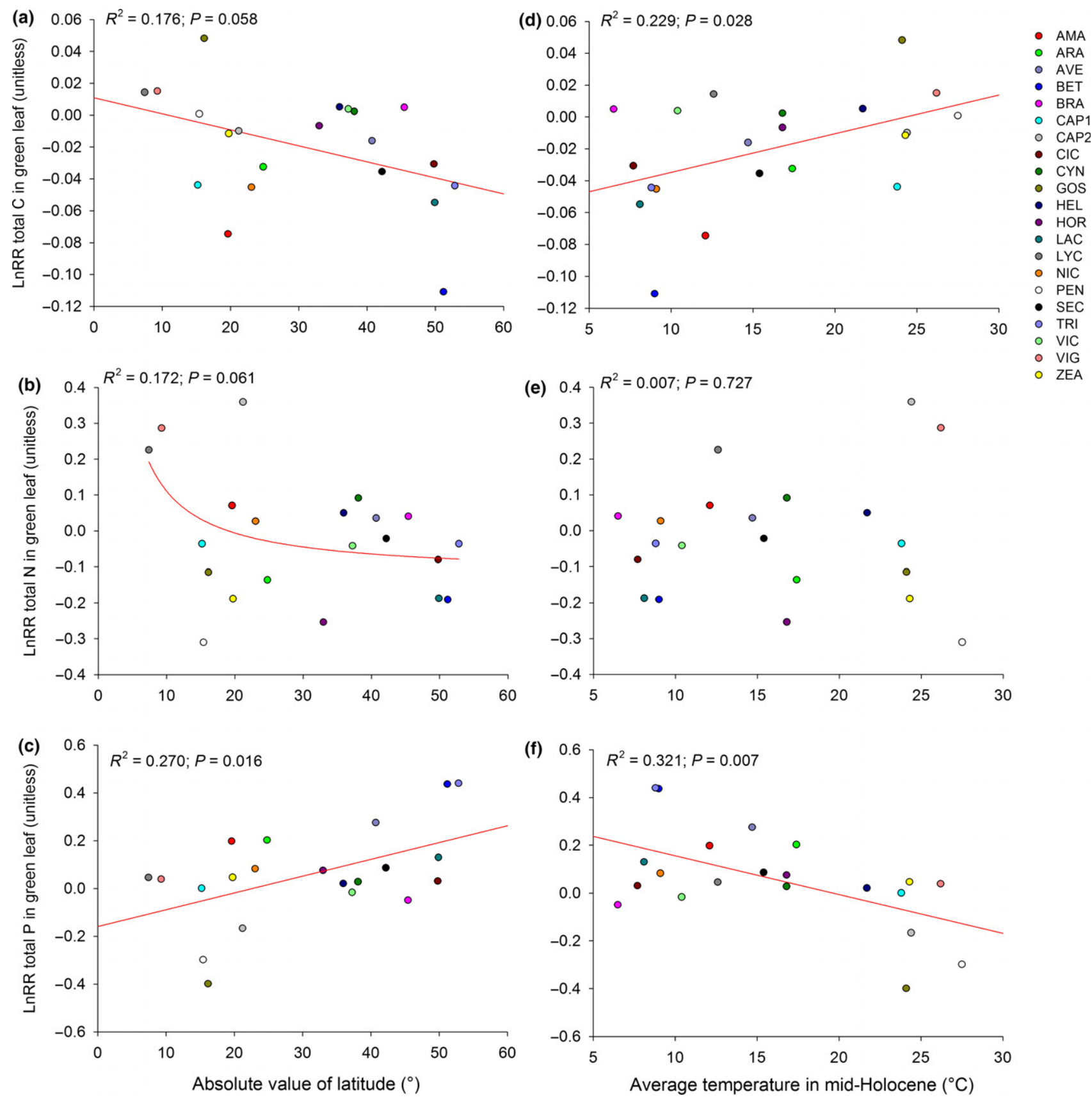

Figure 3 Relationship between absolute latitude (distance from the equator) of the domestication sites and average temperature in mid-Holocene with LnRR-C, $-\mathrm{N}$ and $-\mathrm{P}$ in green leaves. Solid lines represent the fitted linear or inverse regressions.

domestication sites was negatively related to LnRR-P, and positively related to LnRR-C and LNRR-N : $\mathrm{P}$ and $-\mathrm{C}$ : P ratios (Figs 3 and $4 ; P<0.05$ ). Interestingly, crops that increased leaf $\mathrm{P}$ during domestication also decreased leaf $\mathrm{C}$ (Pearson's $\mathrm{r}$ of LnRR-C vs. -P: $-0.725 ; P<0.001$; Fig. S3). We also found a trend for an inverse negative relationship between absolute latitude and LnRR-N (Fig. 3; $P=0.061$ ), suggesting that LnRR-N increases from the middle latitude to the tropics. The relationships between temperature and LnRR indexes were robust to the choice of climate metric (Table S9). Moreover, domestication effects on leaf nutrient concentrations and ratios calculated as LnRR were highly related to the same variable calculated using alternative effect size metrics such as Percentage Change (Pearson's $r>0.95$; $P<0.001$ ), Cohen's D (Pearson's $r>0.80 ; \quad P<0.001$; Table S10) and RII indexes (Pearson's $r>0.98 ; P<0.001$ ). Most importantly, the reported relationships between the distance from the equator and average temperature with domestication effects on leaf nutrient concentrations and ratios are robust to the choice of size-effect index (Table S11).

Finally, results from the litter decomposition experiment tested in two widely different soils showed that shifts in leaf litter $\mathrm{N}, \mathrm{P}$ and $\mathrm{C}: \mathrm{P}$ and $\mathrm{N}$ : $\mathrm{P}$ ratios impacted soil available $\mathrm{N}$ as well as $\mathrm{P}, \mathrm{C}: \mathrm{P}$ and $\mathrm{N}: \mathrm{P}$ ratios $(P \leq 0.05$; Fig. 5; 

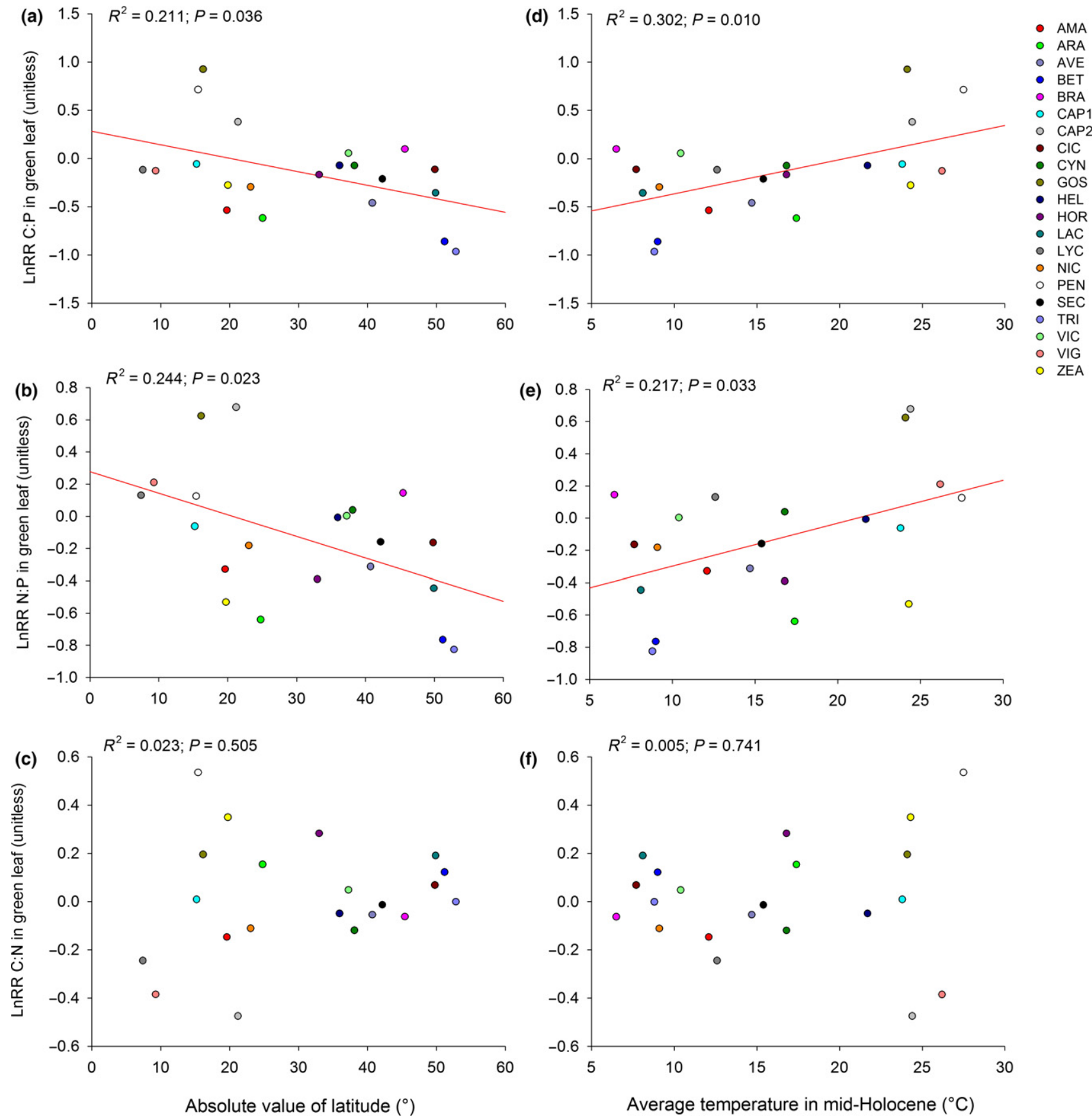

Figure 4 Relationship between absolute latitude (distance from the equator) of the domestication sites and average temperature in the mid-Holocene with LnRR-C : P, -N : P and $-\mathrm{C}: \mathrm{N}$ in green leaves. Solid lines represent the fitted linear regressions.

Table S3; see Methods section for soil properties). However, we did not find any significant relationship between leaf litter $\mathrm{C}$ and dissolved organic $\mathrm{C}$ after the decomposition assay (Table S12).

\section{DISCUSSION}

Domestication pushed increases in leaf $\mathrm{N}$ and/or $\mathrm{P}$ for a majority of the studied crops (Fig. 1), partially supporting the Growth rate hypothesis (i.e. fast-growing organisms increase their nutrient concentrations to support high pro- ductivity; Elser et al. 2000; Peñuelas \& Sardans 2009). Those crops may have evolved to increase their overall nutrient uptake, in order to support high energy demands (e.g. ribosomes, ATP, DNA or RNA) at high productivity rates promoted by human selection. However, they may also allocate less $\mathrm{C}$ to structural support (e.g. structural defences against pests), as suggested by a highly significant negative relationship observed between LnRR-C and -P. Backing that claim, García-Palacios et al. (2013) showed that domesticated plants often have lower leaf litter lignin contents than their wild progenitors. Moreover, shifts in plant chemistry and stoi- 
(a)

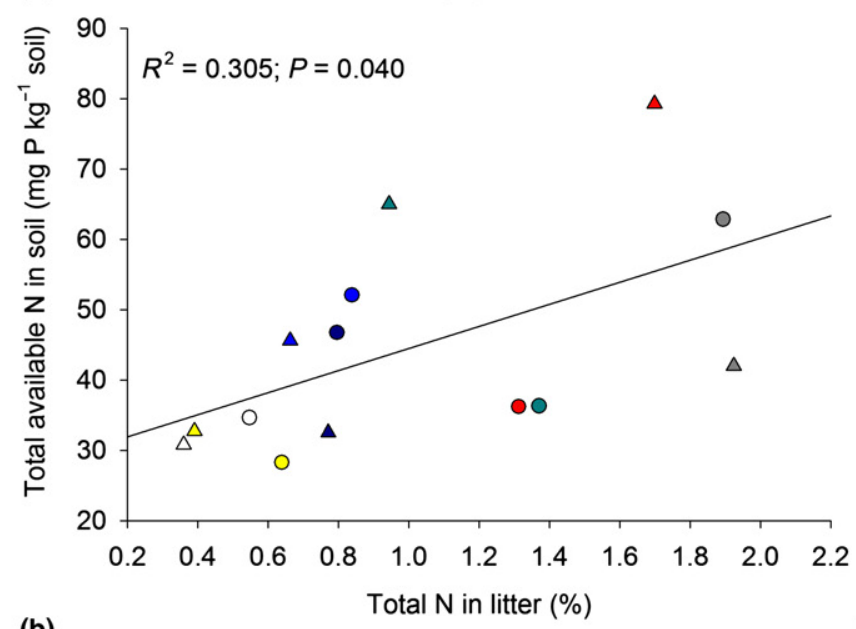

(b)

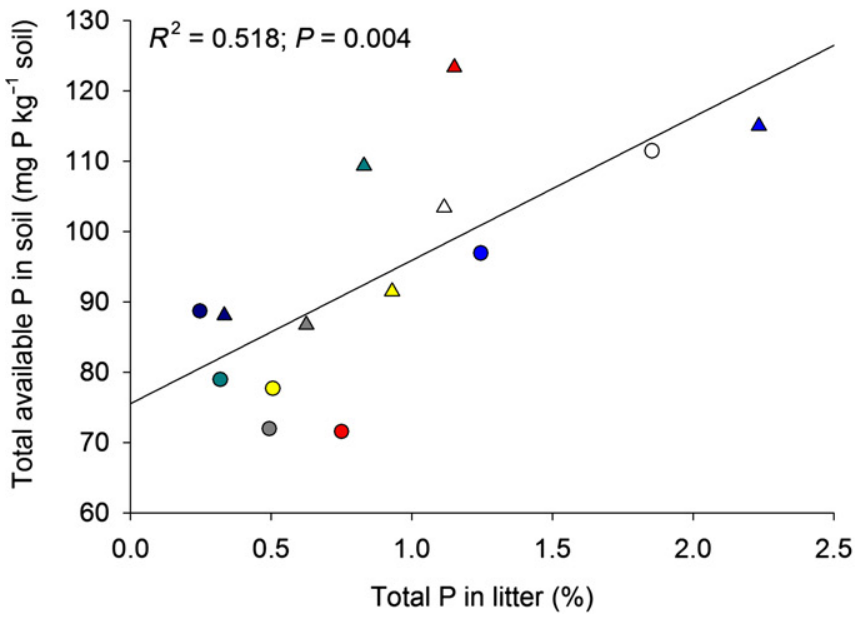

(c)

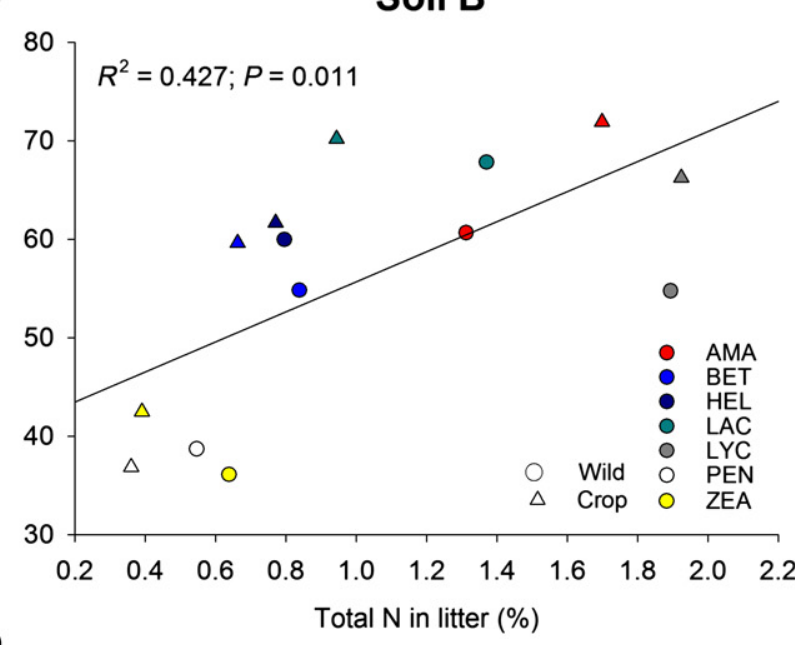

(d)

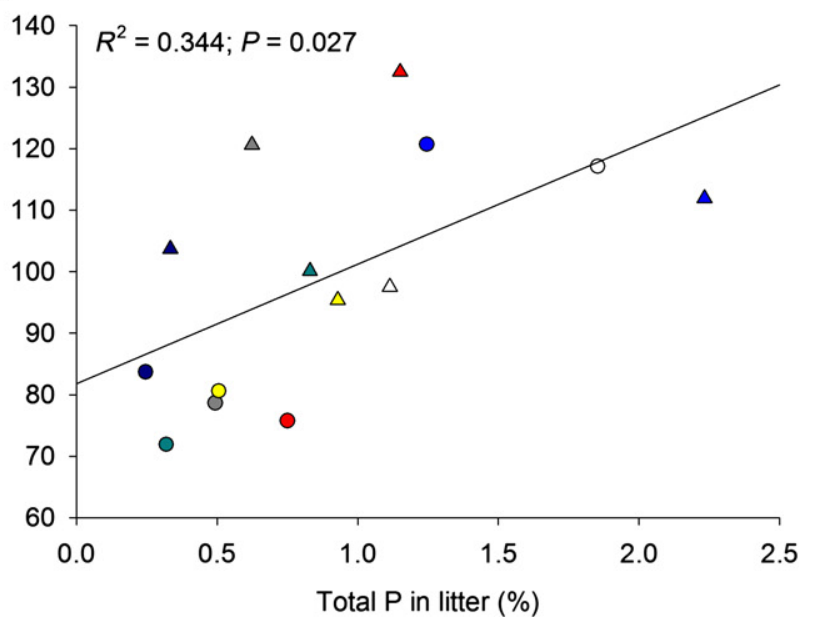

Figure 5 Relationship between mean values of leaf litter and soil $\mathrm{N}$ and $\mathrm{P}$ concentration from the leaf litter decomposition assay $(n=14)$.

chiometries accompanying domestication were highly related to the biogeography and climate of the domestication sites. In line with the Soil Substrate Age (i.e. latitudinal patterns drive $\mathrm{C}, \mathrm{N}$ and $\mathrm{P}$ in plant tissues) and T-Plant physiology hypotheses (i.e. lower temperature at higher latitudes constrain plant physiology), the temperature in the mid-Holocene and/or distance from the equator of the domestication sites modulated domestication effects on plant $\mathrm{C}, \mathrm{N}$ and $\mathrm{P}$ stoichiometry (Reich \& Oleksyn 2004; Fig. 1). In addition, our crop data from middle latitudes vs. tropical zones are consistent with the 'greater stability of the most limiting nutrient hypothesis' put forth by Han et al. (2011), which might suggest that, during domestication, plants adjusted their physiology to increase uptake of both $\mathrm{N}$ and $\mathrm{P}$. The greater availability of the less limiting nutrient means that it will increase more than the most limiting nutrient, which is consistent with evidence of strong shifts in $\mathrm{P}$ in mid-latitudes (where $\mathrm{N}$ is limiting and $\mathrm{P}$ rarely is) and not consistent with shifts in the tropics where both $\mathrm{N}$ and $\mathrm{P}$ are usually limiting. Therefore, although pressure for increasing $\mathrm{N}$ and $\mathrm{P}$ tissue concentrations may have existed during domestication, the effect of this process on plant chemistry was potentially limited by the soil conditions and ancient climate at each particular location.

All progenitor and crop plants were grown under common environmental conditions in this study, hence, minimising the effects of plasticity in response to heterogeneous in situ environments at field sites. Thus, the fact that we found stoichiometry legacies from the original domestication sites suggests that crops should have evolved different nutrient uptake strategies than their wild progenitors. Novel resourceuse strategies may include promotion of the release of extracellular enzyme activities (e.g. phosphatase) and carboxylic acids (e.g. oxalic acid), both of them aiming to increase P acquisition (Lambers et al. 2008). In this regard, it is likely that tropical crops are more dependent on N-rich molecules for P uptake (e.g. phosphatases), whereas plants that have evolved under cultivation in middle latitudes, where $\mathrm{P}$ is a much more abundant soil nutrient (relative to its demand) than N, may have become more proficient in obtaining inorganic P from the bedrock-releasing carboxylic exudates. Consistent with this idea, crop species from genus such as Brassica, Beta and Triticum, which were domesticated in the middle latitudes, have an overall high capacity to mobilise 
inorganic P from soil (El Dessougi et al. 2003; Nuruzzaman et al. 2005; Lambers et al. 2006). On the other hand, Gossypium, which evolved as a crop in locations close to the tropics, uptakes $\mathrm{P}$ at slower rates than other crop species such as Triticum (Wang et al. 2009; Niu et al. 2012). Moreover, P acquisition in Gossypium is linked to the production of N-rich extracellular enzyme activities such as phosphatases (Wang et al. 2009; Niu et al. 2012). These studies support the idea that crops domesticated in the middle latitudes might be more efficient in obtaining inorganic $\mathrm{P}$ from bedrock, whereas the ability of plants domesticated close to the tropics to obtain $\mathrm{P}$ may be linked to the availability of $\mathrm{N}$ (via production of extracellular enzyme activities), often less limiting than $\mathrm{P}$ in the soils from these regions. Remarkably, we lack studies assessing the impact of domestication on root traits favouring diverse nutrient-acquisition strategies; and this serious gap of knowledge needs to be filled in future studies.

Interestingly, only the domestication of Amaranthus promoted a simultaneous increase in both leaf $\mathrm{N}$ and $\mathrm{P}$ compared to its wild progenitor. For all other crops leaf $\mathrm{N}$ and $\mathrm{P}$ evolved independently. The lack of a simultaneous increase in both $\mathrm{N}$ and $\mathrm{P}$ during domestication may be a direct consequence of the underlying control of biogeographical and climatic patterns on $\mathrm{C}, \mathrm{N}$ and $\mathrm{P}$ soil and plant chemistries, reported here and by others (Reich \& Oleksyn 2004). Here, we argue that the higher uptake and accumulation of the more abundant (in relation to demand, see Han et al. 2011) nutrients (i.e. $\mathrm{P}$ in middle latitudes and $\mathrm{N}$ in the tropics) may be critical to support an increase in the uptake efficiency for other limiting nutrients, allowing fast plant growth rates promoted by human selection (Elser et al. 2000; Peñuelas \& Sardans 2009; Ågren et al. 2012). Multiple-element control on plant production has been recently reported in natural ecosystems (See et al. 2015), thus, is likely occurring in agroecosystems. For example, a higher uptake and accumulation of $\mathrm{P}$ in plant tissues is critical to support N-fixation in the mid-latitudinal regions (e.g. legumes such as Arachis and some grasses and cereals such as Triticum, Secale and Avena; Boddey \& Dobereiner 1995; Vitousek et al. 2002). Nitrogen fixation is an energetically expensive process and requires high amounts of $\mathrm{P}$ to support the production of adenosine nucleotides needed to provide energy used in the nitrogenase reaction/in notrogenase reactions (Vitousek et al. 2002). Moreover, N uptake by plants has been reported to increase via high affinity transporters, which depend on its phosphorylation status, and, in turn, on the availability of $\mathrm{P}$ in soil (Garnett et al. 2013; Nacry et al. 2013). Hence, by increasing the accumulation and uptake of $\mathrm{P}$ in mid-latitudes, domestication may have also altered the capacity of plants to obtain the scarcer nutrient, such as $\mathrm{N}$ in mid-latitude regions.

Contrary to our hypothesis (i.e. domestication increase leaf $\mathrm{N}$ and $\mathrm{P}$ ), we also found decreases in leaf $\mathrm{N}$ concentration with domestication in $42 \%$ of the crops evolved in middle latitudes (Fig 2; Table 1). Significant decreases in $\mathrm{N}$ and $\mathrm{P}$ were also found in 17 and $33 \%$, respectively, of the crops domesticated in tropical latitudes. Those results may relate to the local environmental context where each crop was raised. Humans not only imprinted significant effect on the selected species for cultivation but also on the ecosystems where wild plants were domesticated (Milla et al. 2015). For example, cultivation, particularly in recent times, is known to generally reduce the amount of soil organic matter, promoting $\mathrm{C}$ and $\mathrm{N}$ losses to the atmosphere and reducing nutrient availability (Schlesinger 1996). Thus, reductions in crop leaf $\mathrm{N}$ might have been modulated by the reduction in organic matter (i.e. organic $\mathrm{N}$ ) and high $\mathrm{N}$ leaching, derived from human activities in the low-fertilisation environment (i.e. ancient local middle latitude $\mathrm{N}$-poor manure vs. current globally available industrial N-rich fertilisers from Haber process) where these crops where cultivated (but see Bogaard et al. 2013; Araus et al. 2014). Interestingly, decreases in leaf $\mathrm{P}$ during domestication were only detected at tropical regions (Fig. 2). A reduction in organic matter in cultivated environments may have also impacted $\mathrm{P}$ uptake by domesticated plants in these regions where organic $\mathrm{P}$ is an important source of $\mathrm{P}$ (i.e. via $\mathrm{P}$ mineralisation).

Our results also indicated that shifts in plant chemistry with domestication can alter ecosystem processes such as nutrient cycling. The chemistry $(\mathrm{P}, \mathrm{N}, \mathrm{N}: \mathrm{P}$ and $\mathrm{C}: \mathrm{P})$ of leaf litter decomposing in soils was highly related to nutrient cycling properties of those soils (Fig. 4). As a result, domestication legacies on plant chemistry may influence soil fertility via (1) changes in soil chemistry during plant growth, linked to shifts in nutrient-acquisition strategies emerged during domestication and/or later crop evolution; and (2) build-up of soil fertility via litter decomposition, particularly relevant to growing agricultural practices such as in situ management of crop residues or tillage (Guerif et al. 2001). Domestication legacies thus add to other human impacts on agroecosystem soils, such as inorganic fertilisation and the use of pesticides (Vitousek et al. 1997). Furthermore, the phenotypic variation component (e.g. plant stoichiometric shifts) of the domestication process is linked with the decreased genetic diversity in crops relative to the wild ancestors (e.g. tomato, Miller \& Tanksley 1990), although such reduction varies between species (Flint-García 2013). However, studies on maize have proved that only $2-4 \%$ of maize genes experienced selection after 9000 years of domestication from teosinte, leaving vast room for crop phenotypic improvement by breeding. Thus, genome-wide approaches (Wright et al. 2005) coupled with automated phenotypic platforms (Granier et al. 2006) have the potential to lead to important discoveries in the relationship between genetic diversity and phenotypic variation.

Altogether, our findings provide novel evidence that unintentional changes in plant chemistry during domestication may be influenced by the climatic and soil environment in which these crops evolved. Latitudinal gradients in soil $\mathrm{N}$ and $\mathrm{P}$ stoichiometries, driven by soil substrate ages and temperature constraints on plant physiology, play a major role in modulating shifts in leaf stoichiometry during plant domestication. Our results further indicate that domestication legacies on plant chemistry can have a measurable impact on soil nutrient availability through critical processes such as litter decomposition. In general, we posit that the evolutionary legacies of domestication need to be considered together with other agriculture impacts such as fertilisation to accurately assess key ecosystem services (e.g. plant yield and soil fertility) delivered by agriculture. 


\section{ACKNOWLEDGEMENTS}

This research is supported by the Madrid Regional Government (grant REMEDINAL-3), MINECO-Spain (grants CGL2014-56567-R and PCIN-2014-053) and the European Union (Eco-serve project, Biodiversa-FACCI, Horizon 2020). We thank Melchor Maestro, José Margalet, Mónica Álvaro, Nieves Martín and Ana Prado-Comesaña for assistance in data gathering and Melissa S. Martín for revising the English of this manuscript. We also thank Jesus Martinez for his help in graphic designs. P.G-P. was funded by the People Programme (Marie Curie Actions) of the European Union's Seventh Framework Programme (FP7/2007-2013) under REA grant agreement $n^{\circ}$ DECOMFORECO-2011-299214.

\section{AUTHORSHIP}

M.D-B. designed this study in consultation with R.M., P.B.R. and P.G-P. Field data and laboratory analyses were done by M.D-B., P.G-P. and R.M. Data analyses were done by M.D-B. and R.M. The first draft of this study was written by M.D-B.; all subsequent drafts were written collectively by all co-authors.

\section{DATA ACCESSIBILITY}

Data from this study are available in Appendix S2.

\section{REFERENCES}

Ågren, G.I. (2008). Stoichiometry and Nutrition of Plant Growth in Natural Communities. Annu. Rev. Ecol. Evol. Syst., 39, 153-170.

Ågren, G.I., Wettersted, J.Å.M. \& Billberger, M.F.K. (2012). Nutrient limitation on terrestrial plant growth -modeling the interaction between nitrogen and phosphorus. New Phytol., 194, 953-960.

Anderson, M.J. (2001). A new method for non-parametric multivariate analysis of variance. Austral Ecol., 26, 32-46.

Araus, J.L., Ferrio, J.P., Voltas, J., Aguilera, M. \& Buxó, R. (2014). Agronomic conditions and crop evolution in ancient Near East agriculture. Nat. Commun., 5, 3953.

Boddey, R.B. \& Dobereiner, J. (1995). Nitrogen fixation associated with grasses and cereals: recent progress and perspectives for the future. Fert. Res., 42, 241-250.

Bogaard, A., Fraser, R., Heaton, T.H., Wallace, M., Vaiglova, P., Charles, M. et al. (2013). Crop manuring and intensive land management by Europe's first farmers. Proc. Natl Acad. Sci. USA, 110, 12589-12594.

Cornelissen, J.H.C., Quested, H.M., Gwynn-Jones, D., van Logtestijn, R.S.P., de Beus, M.A.H., Kondratchuk, A. et al. (2004). Leaf digestibility and litter decomposability are related in a wide range of subarctic plant species and types. Funct. Ecol., 18, 779-786.

Crews, T.E., Kitayama, K., Fownes, J.H., Riley, R.H., Herbert, D.A., Mueller-Dombois, D. et al. (1995). Changes in soil phosphorus and ecosystem dynamics across a long soil chronosequence in Hawai'i. Ecology, 76, 1407-1424.

Delgado-Baquerizo, M. \& Gallardo, A. (2011). Depolymerization and mineralization rates at 12 Mediterranean sites with varying soil $\mathrm{N}$ availability: a test for the Schimel and Bennett model. Soil Biol. Biochem., 43, 693-696.

Delgado-Baquerizo, M., García-Palacios, P., Milla, R., Gallardo, A. \& Maestre, F.T. (2015). Soil characteristics determine soil carbon and nitrogen availability during leaf litter decomposition regardless of litter quality. Soil Biol. Biochem., 81, 134-142.
Denison, R. (2012). Darwinian Agriculture: How Understanding Evolution Can Improve Agriculture. Princeton University Press, Princeton, US.

Doebley, J.F., Gaut, B.S. \& Smith, B.D. (2006). The molecular genetics of crop domestication. Cell, 127, 1309-1321.

El Dessougi, H., zu Dreele, A. \& Claassen, N. (2003). Growth and phosphorus uptake of maize cultivated alone, in mixed culture with other crops or after incorporation of their residues. J. Plant Nutr. Soil Sci., 166, 254-261.

Elser, J.J., Sterner, R.W., Gorokhova, E., Fagan, W.F., Markow, T.A., Cotner, J.B. et al. (2000). Biological stoichiometry from genes to ecosystems. Ecol. Lett., 3, 540-550.

Evans, L.T. (1993). Crop evolution, adaptation and yield. Cambridge University Press, New York, NY, USA.

Flint-García, S.A. (2013). Genetics and Consequences of Crop Domestication. J. Agr. and Food Chem., 61, 8267-8276.

García-Palacios, P., Milla, R., Delgado-Baquerizo, M., Martín-Robles, N., Álvaro-Sánchez, M. \& Wall, D.H. (2013). Side effects of plant domestication: ecosystem impacts of changes in litter quality. New Phyt., 198, 504-513.

Garnett, T., Appleby, M.C., Balmford, A., Bateman, I.J., Benton, T.G., Bloomer, P. et al. (2013). Sustainable intensification in agriculture: premises and policies. Science, 341, 33-34.

Granier, C., Aguirrezabal, L., Chenu, K., Cookson, S.J., Dauzat, M., Hamard, P. et al. (2006). PHENOPSIS, an automated platform for reproducible phenotyping of plant responses to soil water deficit in Arabidopsis thaliana permitted the identification of an accession with low sensitivity to soil water deficit. New Phyt., 169, 623-635.

Guerif, J., Richard, G., Durr, C., Machet, J.M., Recous, S. \& RogerEstrade, J. (2001). A review of tillage effects on crop residue management, seedbed conditions and seedling establishment. Soil Till. Res., 61, 13-32.

Han, W., Fang, J., Woodward, F.I., Reich, P.B. \& Wang, Z. (2011). Biogeography and variability of eleven mineral elements in plant leaves across gradients of climate, soil, and plant functional type in China. Ecol. Lett., 14, 788-796.

Hancock, J.F. (2004). Plant evolution and the origin of crop species. CABI Publishing, Oxon, UK.

Harlan, J.R., de Wet, J.M.J. \& Price, G.E. (1973). Comparative evolution of cereals. Evolution, 27, 311-325.

Hedges, L.V., Gurevitch, J. \& Curtis, P.S. (1999). The meta-analysis of response ratios in experimental ecology. Ecology, 80, 1150-1156.

Hijmans, R.J., Cameron, S.E., Parra, J.L., Jones, P.G. \& Jarvis, A. (2005). Very high resolution interpolated climate surfaces for global land areas. Int. J. Climatol., 25, 1965-1978.

Lambers, H., Shane, M.W., Cramer, M.D., Pearse, S.J. \& Veneklaas, E.J. (2006). Root structure and functioning for efficient acquisition of phosphorus: matching morphological and physiological traits. Ann. Bot., 98, 693-713.

Lambers, H., Chapin, F.S. \& Pons, T.L. (2008). Plant Physiological Ecology, Ed 2. Springer, NY, USA.

Larson, G., Piperno, D.R., Allaby, R.G., Purugganan, M.D., Andersson, L., Arroyo-Kalin, M. et al. (2014). Current perspectives and the future of domestication studies. Proc. Natl Acad. Sci. USA, $111,6139-6146$.

Marsh, W.M. \& Kaufman, M. (2013). Physical Geography: great Systems and Global Environments. Cambridge University Press, Cambridge, UK.

Meyer, R.S. \& Purugganan, M. (2013). Evolution of crop species: genetics of domestication and diversification. Nat. Rev. Genet., 14, 840-852.

Meyer, R.S., DuVal, A.E. \& Jensen, H.R. (2012). Patterns and processes in crop domestication: an historical review and quantitative analysis of 203 global food crops. New Phytol., 196, 29-48.

Milla, R., Morente-López, J., Alonso-Rodrigo, J.M., Martín-Robles, N. \& Chapin, F.S. III (2014). Shifts and disruptions in resource-use trait syndromes during the evolution of herbaceous crops. Proc. R. Soc. B, 281, 20141429

Milla, R., Osborne, C.P., Turcotte, M.M. \& Violle, C. (2015). Plant domestication through an ecological lens. Trends Ecol. Evolut., 30, 463-469. 
Miller, J.C. \& Tanksley, S.D. (1990). RFLP analysis of phylogenetic relationships and genetic variation in the genus Lycopersicon. Theor. Appl. Genet., 80, 437-448.

Nacry, P., Bouguyon, E. \& Gojo, A. (2013). Nitrogen acquisition by roots: physiological and developmental mechanisms ensuring plant adaptation to a fluctuating resource. Plant Soil, 370, 1-29.

Niu, J.F., Chai, R.S., Jin, J.L., Wang, H., Tang, C.X. \& Zhang, Y.S. (2012). Responses of root architecture development to low phosphorus availability: a review. Ann. Bot., 112, 391-408.

Nuruzzaman, M., Lambers, H., Bolland, M.D.A. \& Veneklaas, E.J. (2005). Phosphorus uptake by grain legumes and subsequently grown wheat at different levels of residual phosphorus fertiliser. Austr. J. Agricult. Res., 56, 1041-1047.

Peñuelas, J. \& Sardans, J. (2009). Elementary factors. Nature, 460, 803804.

Reich, P.B. \& Oleksyn, J. (2004). Global patterns of plant leaf N and P in relation to temperature and latitude. Proc. Natl Acad. Sci. USA, 101, 11001-11006.

Reich, P.B., Ellsworth, D.S. \& Walters, M.B. (1991). Leaf development and season influence the relationships between leaf nitrogen, leaf mass per area, and photosynthesis in maple and oak trees. Plant, Cell Environ., 14, 251-259.

Sardans, J., Rivas-Ubach, A. \& Peñuelas, J. (2012). The elemental stoichiometry of aquatic and terrestrial ecosystems and its relationships with organismic lifestyle and ecosystem structure and function: a review and perspectives. Biogeochemistry, 111, 1-39.

Schlesinger, W.H. (1996). Biogeochemistry, an analysis of global change. Academic Press, San Diego, CA, USA.

See, C.R., Yanai, R.D., Fisk, M.C., Vadeboncoeur, M.A., Quintero, B.A. \& Fahey, T.J. (2015). Soil nitrogen affects phosphorus recycling: foliar resorption and plant-soil feedbacks in a northern hardwood forest. Ecology, 96, 2488-2498.

Tiessen, H. \& Moir, J.O. (1993). Soil sampling and method of analysis. Lewis publisher, Boca Raton, FL, USA.

Tribouillois, H., Fort, F., Cruz, P., Charles, R., Flores, O., Garnier, E. et al. (2015). A Functional Characterisation of a Wide Range of Cover CropSpecies: Growth and Nitrogen Acquisition Rates, Leaf Traits and Ecological Strategies. PLoS ONE, 10, e0122156.
Turcotte, M.M., Turley, N.E. \& Johnson, M.T. (2014). The impact of domestication on resistance to two generalist herbivores across 29 independent domestication events. New Phytol., 204, 671-681.

Vitousek, P.M., Aber, J.D., Howarth, R.W., Aber, J.D., Howarth, R.W., Likens, G.E. et al. (1997). Human alteration of the global nitrogen cycle: sources and consequences. Ecol. Appl., 7, 737-750.

Vitousek, P.M., Cassman, K., Cleveland, C., Crews, T., Field, C.B., Grimm, N.B. et al. (2002). Towards an ecological understanding of biological nitrogen fixation. Biogeochemistry, 57, 1-45.

Wang, X., Tang, C., Guppy, C.N. \& Sale, P.W.G. (2009). The role of hydraulic lift and subsoil $\mathrm{P}$ placement in $\mathrm{P}$ uptake of cotton (Gossypium hirsutum L.). Plant Soil, 325, 263-275.

Wright, S.I., Bi, I.V., Schroeder, S.G., Yamasaki, M., Doebley, J.F., McMullen, M.D. et al. (2005). The effects of artificial selection on the maize genome. Science 308, 1310-1314.

Wu, T., Li, W., Ji, J., Xin, X., Li, L., Wang, Z. et al. (2013). Global carbon budgets simulated by the Beijing Climate Center Climate System Model for the last century. J. Geophys. Res.-Atmos., 118, 43264347.

Zechmeister-Boltenstern, S., Keiblinger, k.m., Mooshammer, M., Peñuelas, J., Richter, A., Sardans, J. et al. (2015). The application of ecological stoichiometry to plant-microbial-soil organic matter transformations. Ecol. Monogr., 85, 133-155.

\section{SUPPORTING INFORMATION}

Additional Supporting Information may be downloaded via the online version of this article at Wiley Online Library (www.ecologyletters.com).

Editor, Christoph Scherber

Manuscript received 10 December 2015

First decision made 12 January 2016

Manuscript accepted 4 February 2016 